\title{
Observações sobre o ciclo de vida da corvina, Micropogonias furnieri (Desmarest) (Teleostei, Sciaenidae), no litoral do Estado do Paraná, Brasil ${ }^{1}$
}

\author{
Maurício de Castro Robert ${ }^{2}$ \\ Paulo de Tarso C. Chaves ${ }^{2}$
}

\begin{abstract}
Remarks about the life cycle of the croaker, Micropogonias furnieri (Desmarest) (Teleostei, Sciaenidae), in the Paraná coast, Brazil. A survey performed in the Guaratuba Bay $\left(25^{\circ} 52^{\prime} \mathrm{S} ; 48^{\circ} 39^{\prime} \mathrm{W}\right)$ and the adjacent marine area has provided additional data about the habits of the croaker in the southern coast of Brazil. A dynamic pattern of movements along the marine and estuarine waters was observed, but it does not indicate spawning activity in the study area. During autumn/winter, pre-adults and adults use the marine waters. In spring/summer, following gonadal maturation, the individuals leave this area and probably move to deeper waters, where they spawn. Until the end of summer, the estuary is then occupied by juveniles coming from the marine spawning area. In autumn/winter, these juveniles and the new pre-adults move to the marine zone adjacent to the bay and begin gonadal maturation. It is suggested that the Guaratuba Bay and the adjacent marine area constitute an important site for growth and recruitment of the early life stages of $M$. furnieri and initial stages of reproductive activity.

KEY WORDS. Sciaenidae, Micropogonias furnieri, occupation, estuaries, Brazil
\end{abstract}

A corvina, Micropogonias furnieri (Desmarest, 1823) (Teleostei, Sciaenidae), tem uma expressiva participação nos desembarques pesqueiros artesanais e industriais no Atlântico Sul Ocidental, em particular no sul-sudeste do Brasil, no Uruguai e na Argentina (ACUÑA et al. 1992; PAIVA 1997). Em conseqüência de seu valor econômico e ampla área de distribuição, é uma espécie biologicamente bem conhecida (VAZzoler 1991). Estima-se que o ciclo de vida dos indivíduos depende dos ambientes marinho e estuarino, envolvendo deslocamentos entre áreas mais afastadas e mais próximas da costa (MENEZES \& FigueIREDo 1980; VIEIRA et al. 1998), e a exibição no interior dos estuários de um padrão de movimentos dependente da salinidade (GRAÑA \& PIÑEIRO 1998). A desova, porém, parece ocorrer apenas em áreas mais abertas, a uma certa distância das praias (ACUÑA et al. 1992; HAIMOVICI et al. 1996).

Se por um lado o conhecimento sobre a espécie é grande, por outro existem lacunas de informações quanto às populações em diversos trechos da costa sul do Brasil. Este é o caso do litoral do Paraná, onde a corvina ainda não foi abordada de forma autoecológica, mas apenas integrando inventários ou estudos referentes à comunidade de peixes como um todo. A ocorrência da espécie nos dois sistemas estuarinos locais, o Complexo Baía de Paranaguá e a Baía de Guaratuba (Henry L.

1) Contribuição número 1219 do Departamento de Zoologia, Universidade Federal do Paraná.

2) Departamento de Zoologia, Universidade Federal do Paraná. Caixa Postal 19020, 81531-990 Curitiba, Paraná, Brasil. Bolsista do CNPq. E-mail: poissons@cce.ufpr.br

Revta bras. Zool. 18 (2): 421 - 428, 2001 
Spach comunicação pessoal; CHAVES \& CORRÊA 1998), indica que eles são importantes para o seu ciclo de vida. O presente trabalho avalia a utilização que a corvina faz, durante ao menos uma parte de seu ciclo de vida, do sistema costeiro composto pela Baía de Guaratuba e plataforma continental rasa adjacente.

\section{MATERIAL E MÉTODOS}

\section{Coleta de material}

As coletas foram realizadas em duas fases. A primeira, no interior da Baía de Guaratuba (2552'S; 483' W) (Fig. 1), constou de duas etapas envolvendo coletas mensais, porém em períodos e locais distintos: Etapa I, entre setembro de 1993 e fevereiro de 1997 (exceto maio de 1995), no manguezal situado na área norte da Baía; utilizando rede de arrasto de fundo tipo camaroneira, malha $20 \mathrm{~mm}$ entre nós opostos, com semelhante esforço mensal; e Etapa II, entre maio de 1998 e abril de 1999, em três áreas ao longo de um transecto situado fora do manguezal da etapa anterior, desde a foz do rio Guanxuma (área 1, "interna") até a proximidade do canal de ligação da Baía com o mar (área 3, "externa"), com uma área "intermediária" (2). Nesta etapa, os exemplares foram capturados com rede de arrasto de fundo idêntica à da etapa anterior, bem como com rede de emalhar (malha $70 \mathrm{~mm}$ entre nós opostos), ambas com esforço semelhante em todos os meses. A segunda fase transcorreu no setor de plataforma continental rasa $20 \mathrm{Km}$ ao norte da Baía $\left(25^{\circ} 45^{\prime} \mathrm{S}\right.$; $48^{\circ} 20^{\prime} \mathrm{W}$ ), entre profundidades de 10 e 15 metros (Fig. 1), constando de coletas mensais entre março de 1999 e janeiro de 2000 (exceto setembro), e empregando rede tipo camaroneira com malha semelhante à da fase anterior.

Objetivando aumentar o tamanho da amostra para o cálculo da relação peso/comprimento dos indivíduos, neste item utilizaram-se também os dados obtidos em operações-piloto prévias à primeira fase, na área de manguezal da Baía. Estas foram realizadas em julho e agosto de 1993, empregando redes de arrasto de fundo e de emalhar, sem esforço controlado.

\section{Processamento laboratorial e tratamento dos dados}

Transferidos para laboratório sob refrigeração, os exemplares foram medidos (comprimento total, CT) e pesados (PT). Análise gonadal foi efetuada para estimativa do sexo e estádio de maturação, baseada em VAzzoler (1996). Dados de captura por unidade de esforço consideraram que o esforço realizado foi diferente entre as três etapas, validando as comparações sazonais de abundância apenas quando referentes a uma mesma etapa. Janeiro, fevereiro e março compuseram o verão, e assim sucessivamente. Para comparação da estrutura em tamanho entre os locais, somente as operações de arrasto foram consideradas, eliminando-se, assim, a influência da seletividade da rede de emalhar (Etapa II da primeira fase).

\section{RESULTADOS}

\section{Abundância}

Maiores valores de captura por esforço foram registrados em épocas diferentes, segundo a região: no interior da Baía, durante primavera/verão; na plataforma, durante outono/inverno (Fig. 2). No transecto interior à Baía, M. furnieri esteve 
presente, em todas as estações do ano, nas áreas interna (exceto no inverno), intermediária e externa. No outono e na primavera, houve maior abundância de indivíduos na área interna; no verão, na área intermediária; e no inverno, na área externa (Fig. 3).

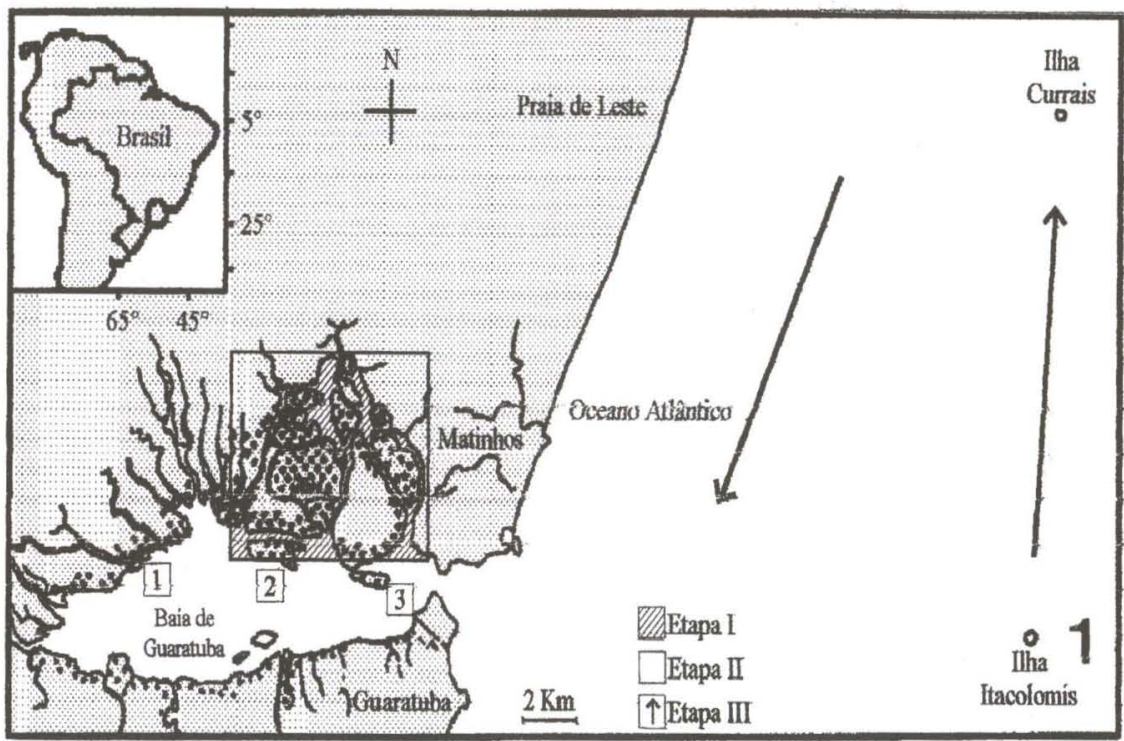

Fig. 1. Mapa da região de estudo, litoral do Estado do Paraná, indicando o local de realização de cada etapa. 1, 2 e 3: áreas de coleta na Etapa II.

\section{Tamanho individual}

No interior da Baía (Etapas I e II), os exemplares foram distribuídos em quatro classes de tamanho, entre 50 e $561 \mathrm{~mm}$. A classe de tamanho menor foi registrada em freqüências decrescentes da primavera para o início do outono, enquanto a imediatamente maior $o$ foi em freqüências crescentes do verão para o inverno (Fig. 4). As duas outras classes representadas foram registradas apenas de meados de inverno a meados de primavera. Na Etapa II, apenas as duas classes de menor tamanho estiveram representadas. Os indivíduos da classe $50-135 \mathrm{~mm}$ foram capturados principalmente na área mais interna, enquanto indivíduos com $135 \mathrm{~mm}$ ou mais foram capturados nas três áreas em abundância semelhante (Fig. 5).

Na plataforma, os exemplares distribuíram-se numa amplitude de tamanho menor que na Baía, com intervalo entre 139 e $283 \mathrm{~mm}$. A classe de tamanho menor alcançou maior freqüência no verão e outono; a de tamanho intermediário, no outono e inverno; e a de tamanho maior na primavera (Fig. 6).

A equação peso/comprimento, obtida a partir de exemplares capturados na Baía e na plataforma, foi $\mathrm{PT}=4,33 \cdot 10^{-6} \mathrm{CT}^{3,17}(\mathrm{n}=342 ; \mathrm{r}=0,987)$, podendo ser utilizada para comparação com a de outras populações da espécie. 

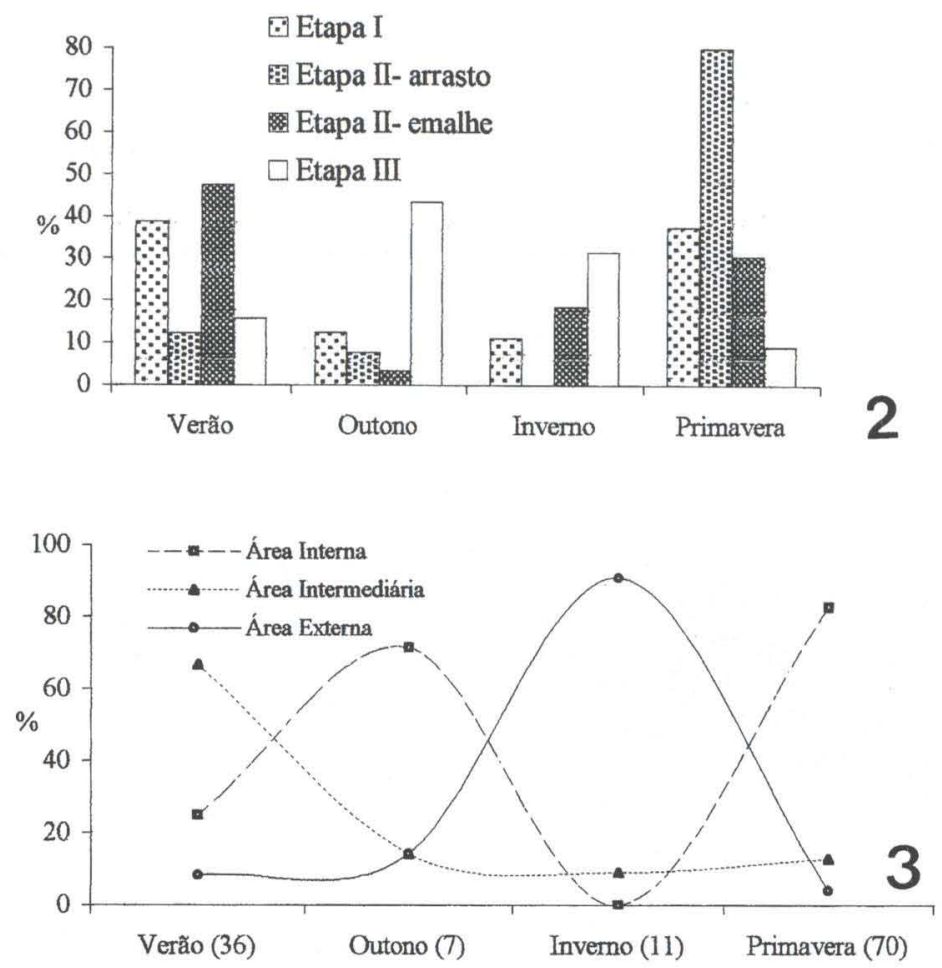

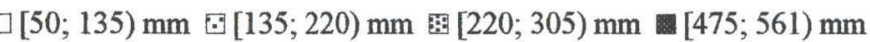

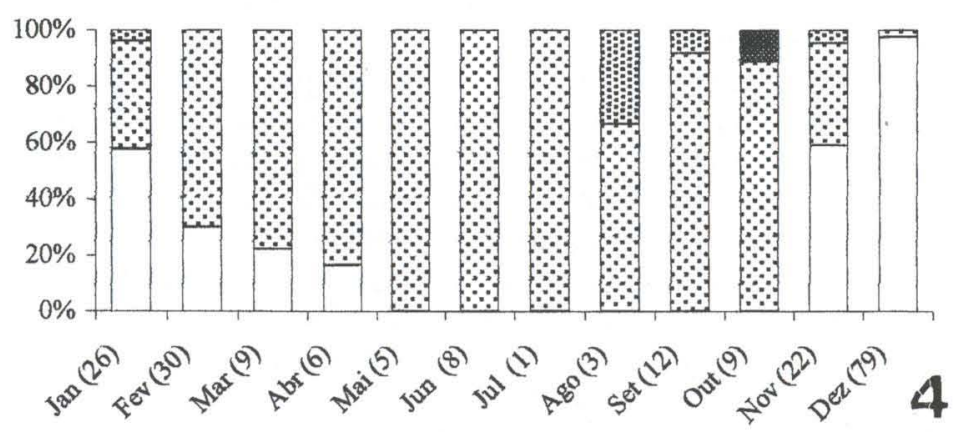

Figs 2-4. (2-3) Distribuição relativa da abundância numérica de $M$. furnierinas capturas (arrasto e emalhe) segundo a estação e a Etapa (2) e a (3) área do transecto interior à Baia; (4) participação relativa das classes de tamanho (comprimento total em $\mathrm{mm}$ ) de $M$. furnieri capturada com rede de arrasto no interior da Baía de Guaratuba, Etapas I + II, segundo o mês. (I) Manguezal da Baía, $n=145$; (II) transecto áreas 1, 2 e 3 da Baía, arrasto $n=65$, emalhe = 59; (III) plataforma, $n=65$. Interna: 1; Intermediária: 2; Externa: 3. Entre parênteses, o tamanho da amostra. 
CT: $[50 ; 135) \mathrm{mm}$

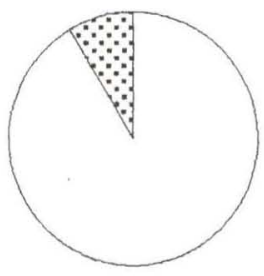

CT: $[135 ; 561) \mathrm{mm}$

$\square$ Área 1

$Q$ Área 2

㫜 Área 3

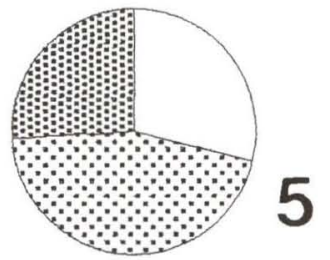

‥ $[139 ; 187) \mathrm{mm}$ 용 $[187 ; 235) \mathrm{mm}$ 밈 $[235 ; 284) \mathrm{mm}$

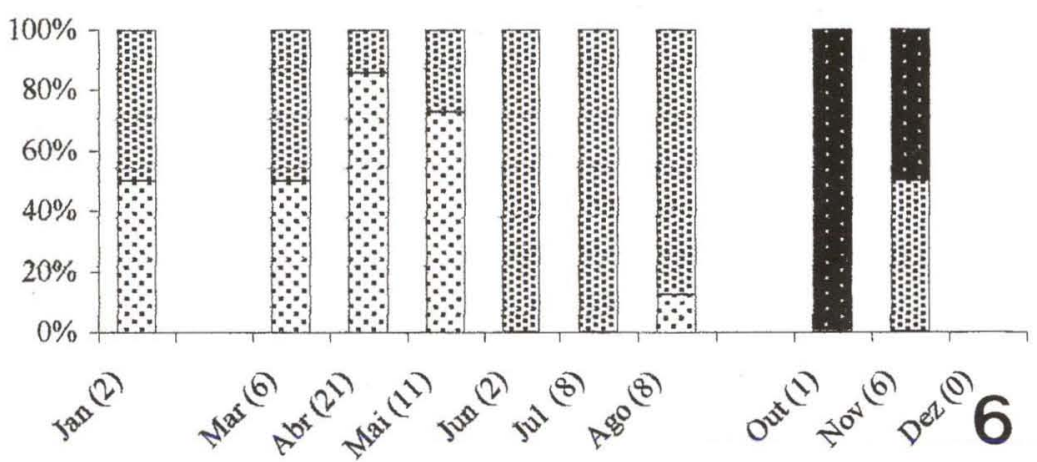

Figs 5-6. (5) Captura proporcional de M. furnieri na Baia de Guaratuba segundo a área (1: Interna, 2: Intermediária, 3: Externa; Etapa II, arrasto + emalhe), nas duas classes de tamanho presentes (CT - comprimento total). Tamanho das amostras: $[50 ; 135) \mathrm{mm}=58 ;[135 ; 161)$ $\mathrm{mm}=66$. (6) Participação relativa das classes de tamanho (comprimento total em $\mathrm{mm}$ ) de $M$. furnieri capturada com rede de arrasto na plataforma adjacente à Baía de Guaratuba, profundidade 10-15m (Etapa III), segundo o mês. Entre parênteses, o tamanho da amostra.

\section{Reprodução}

Indivíduos em maturação foram encontrados nos três locais de estudo, mas a época em que ocorreram com maior freqüência nas amostras divergiu entre eles: na Etapa I, maior freqüência de indivíduos em maturação foi registrada no final do inverno; na Etapa II, no verão; e na Etapa III, na primavera (Fig. 7). Indivíduos maduros foram encontrados apenas no manguezal da Baía (Etapa I), no final do inverno e na primavera (Fig. 7).

\section{DISCUSSÃO}

Várias evidências indicam que o ciclo de vida de M. furnieri, na área estudada, segue o comportamento de populações de outras regiões da costa brasileira, envolvendo a utilização de estuários e sistemas lagunares rasos durante uma fase do desenvolvimento, com subseqüente saída para desova em áreas de profundidade superior a 30 metros (VAZZOLER 1991). Na Baía de Guaratuba os indivíduos são mais abundantes na primavera e no verão, enquanto na plataforma durante o outono e inverno, fato que 

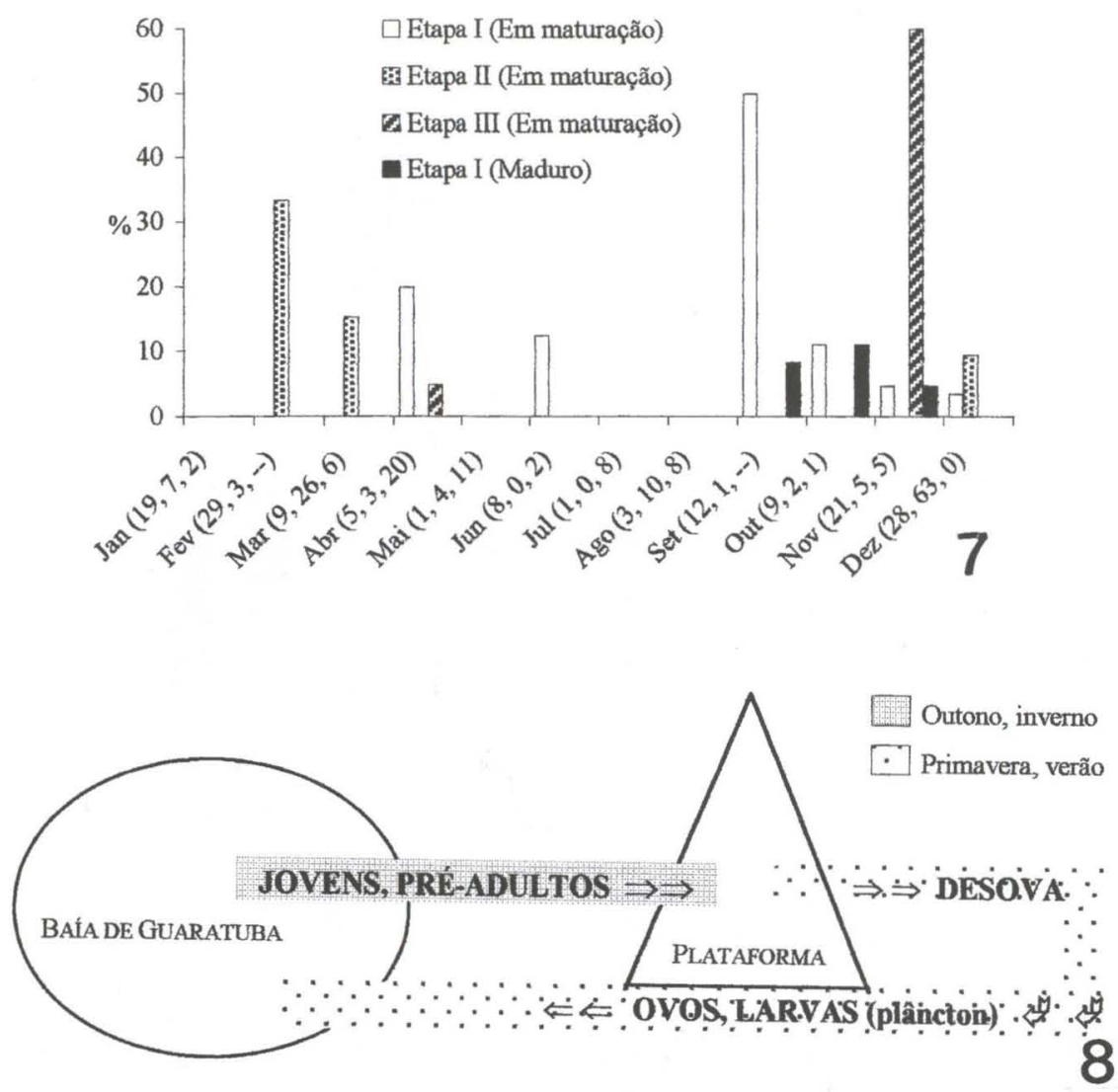

Figs 7-8. (7) Distribuição dos valores de abundância de exemplares de M. furnieri nos estágios "Em maturação" e "Maduro", relativamente ao total de individuos capturados no mês e Etapa em questão. Entre parênteses, junto aos meses: tamanho da amostra nas Etapas I, II e III, respectivamente. (-) Ausência de amostragem. (8) Representação esquemática dos movimentos de $M$. furnieri no setor estudado, envolvendo a Baia de Guaratuba e a plataforma rasa adjacente (profundidade $10-15 \mathrm{~m}$ ), a partir dos dados obtidos neste trabalho e de algumas informações de literatura sobre hábitos da espécie comentadas no texto.

sugere a existência de deslocamentos de contingente populacional entre uma região e outra. Não há evidências de que ocorra desova na área estudada, fato explicável por sua profundidade limitada a 15 metros. Uma pequena parcela dos indivíduos amostrados possuía tamanho próximo ao estimado para primeira maturação $(250-275 \mathrm{~mm}$ - VAZZOLER 1971), e poucos maduros foram encontrados. Deste modo, as variações sazonais de abundância nas duas sub-áreas - Baía e plataforma - apontam para a seguinte dinâmica: (1) pré-adultos passam o outono/inverno na plataforma rasa e deslocam-se para locais de maior profundidade, onde desovam na primavera/verão; (2) os adultos pós-desova não retornam (com exceções: raros exemplares de grande porte foram registrados em Guaratuba), mas têm seus ovos e larvas carreados para a 
zona costeira; e (3) ovos e/ou larvas e/ou juvenis entram, então, na Baía, onde juvenis e pré-adultos são recrutados, aí permanecendo até o início do outono. Na condição de pré-adultos ou adultos em maturação, esses indivíduos se deslocam nesta época para a plataforma rasa, onde permanecem até prosseguirem para a área de desova (Fig. 8).

A expressiva ocorrência de indivíduos de pequeno porte no interior da Baía, notadamente em sua área mais interna, confirma o recrutamento durante a primavera/verão. A ausência de indivíduos menores que $50 \mathrm{~mm}$ não deve ser atribuída à seleção por arte de pesca, visto que indivíduos de outras espécies de Perciformes, com forma do corpo semelhante e de tamanho inferior a este, foram capturados nas mesmas operações. Tampouco pode decorrer de uma distribuição marginal dos exemplares de pequeno porte, pois arrastos de praia com rede tipo picaré, executados ao longo de um ano, não registraram a espécie em marismas da Baía (Ana Lúcia Vendel comunicação pessoal). Duas possibilidades são, então, apresentadas: ou o ingresso na Baía ocorre apenas na forma juvenil, próximo a $50 \mathrm{~mm}$, ou ovos e larvas ingressam na Baía, mas não são capturados em vista de seu hábito planctônico. De fato, VIEIRA et al. (1998) reportam que ovos e larvas de corvina podem ingressar passivamente no estuário da Lagoa dos Patos, e que a mudança de hábito planctônico para demersal ocorre no comprimento de 30 mm (GONÇALVES et al. 1999). O período em que juvenis e pré-adultos permanecem na Baía coincide com águas de fortes características continentais (CHAVES et al. 2000), condições essas já conhecidas para as fases iniciais de vida de $M$. furnieri (ACUÑA et al. 1992).

Conclui-se que a Baía de Guaratuba, sobretudo em seu setor mais interno, é utilizada de forma regular no desenvolvimento de fases jovens de $M$. furnieri, enquanto o conjunto "Baía + plataforma até 15 metros" o é no circuito de pré-adultos e adultos. Embora participe do processo de maturação reprodutiva, a região estudada não constitui local de desova para a espécie.

\section{REFERÊNCIAS BIBLIOGRÁFICAS}

Acuña, A.A.; J. Verocal \& S. Marquez. 1992. Aspectos biologicos de Micropogonias furnieri (Desmarest, 1823) durante dos zafras en una pesqueria artesanal al oeste de Montevideo. Rev. Biol. Mar., Valparaíso, 27 (1): 113-132.

Chaves, P.T.C.; J.-L. Bouchereau \& A.L. Vendel. 2000. The Guaratuba Bay, Paraná, Brazil (2552'S; $48^{\circ} 39^{\prime} \mathrm{W}$ ), in the life cycle of coastal fish species. International Conference Sustainability of Estuaries and Mangroves: Challenges and Prospects. (Recife, Brazil, 22-28 May 2000). Published in CD-rom by Universidade Federal Rural de Pernambuco.

CHAvES, P.T.C. \& M.F.M. CORRÊA. 1998. Composição ictiofaunística da área de manguezal da Baía de Guaratuba, Estado do Paraná, Brasil (2552'S; 48³9'W). Revta bras. Zool. 15 (1): 195-202.

GonçAlves, A.A.; J.A.F. Souz^ \& J.P. Vieir^. 1999. Descrição trófica dos primeiros estágios de vida de Micropogonias furnieri (Sciaenidae) no estuário da Lagoa dos Patos, RS, Brasil. Atlântica, Rio Grande, 21: 93-103.

Graña, F. \& D. PIÑEIRO. 1998. Pesca artesanal em Pajas Blancas: la percepcion de los pescadores sobre la corvina y su ambiente, p. 229-245. In: P.G. Wells \& G.R. DABORN (Ed.). El Río de la Plata una Revision Ambiental. Halifax, Universidad de Dalhousie, 256p.

Halmovicl, M.; A.S. Martins \& P.C. VieirA. 1996. Distribuição e abundância de peixes teleósteos demersais sobre a Plataforma Continental do sul do Brasil. Rev. Brasil. Biol. 56 (1): 27-50. 
Menezes, N.A. \& J.L. Figueiredo. 1980. Manual de Peixes Marinhos do Sudeste do Brasil. IV.

Teleostei (3). São Paulo, Museu de Zoologia, Univ. São Paulo, 96p.

PaIVA, M.P. 1997. Recursos Pesqueiros Estuarinos e Marinhos do Brasil. Fortaleza, UFC Edições, 286p.

VAzzoler, A.E.A. DE M. 1971. Diversificação fisiológica e morfológica de Micropogon furnieri

(Desmarest, 1822) ao sul de Cabo Frio, Brasil. Bolm Inst. Oceanogr. São Paulo 20 (2): 1-70.

1991. Síntese de conhecimentos sobre a biologia da corvina Micropogonias furnieri

(Desmarest, 1823) da costa do Brasil. Atlântica, Rio Grande, 13 (1): 55-74.

. 1996. Biologia da Reprodução de Peixes Teleósteos: Teoria e Prática. Maringá, EDUEM, $169 \mathrm{p}$.

Vieira, J.P.; J.P. CAstello \& L.E. Pereira. 1998. Ictiofauna, p. 60-68. In: U. Seeliger; C. Odebrecht

\& J.P. Castello (Eds). Os Ecossistemas Costeiro e Marinho do Extremo Sul do Brasil. Rio Grande, Ecoscientia, 326p.

Recebido em 13.VII.2000; aceito em 15.V.2001.

Revta bras. Zool. 18 (2): 421 - 428, 2001 